\title{
Abnormal course of right renal artery and ovarian vessels: a Case Report
}

\author{
Abdoalmonim abdoalrahman Mohammed, M.sc * \\ Prof. U.K.Gupta. M.D Med, Ph.D**Mohaned Mohamed abass M.sc *** \\ Department, of anatomy, university of Kassala, Sudan * \\ Department of anatomy, NIMS Medical college, India ** \\ Department of physiology, University of kassala, Sudan***
}

\begin{abstract}
Knowledge of variations of blood vessels in the renal hilum region is important during operative, diagnostic and endovascular procedures in the abdomen. This report describes the variations found in the origin and course of the right renal and ovarian vessels. The variation was found during routine dissection in an approximately 63 years old female cadaver. The cadaver did not have any other observable anomalies in the other parts of the body. The right renal artery originated as the ventral branch of aorta and passed anterior to the inferior vena cava before reaching the hilum of the right kidney. The Right ovarian artery took its origin from the right renal artery. The right ovarian vein was very large and it received two considerably large tributaries from the pararenal pad of fat. The knowledge of variations of renal and gonadal vessels is important for surgeons doing kidney transplants.
\end{abstract}

Keywords: kidney, ovarian artery, ovarian vein, right renal artery, variations

\section{Introduction:}

Renal arteries are a pair of lateral branches from abdominal aorta. Normally each kidney receives one renal artery. However, presence of accessory renal arteries is well known. The normal renal arteries make their way to the kidney through its hilum where as the accessory renal arteries might enter the kidney through the hilum, through the surfaces or the poles of the kidney. The ovarian arteries are braches of abdominal aorta. However, they may also arise from the renal arteries. The ovarian veins are two in number. The right ovarian vein drains the right ovary into the inferior vena cava and the left ovarian vein drains the left ovary into the left renal vein. A sound knowledge of the variations in the renal and gonadal vessels is important for urologists, radiologists and surgeons in general. The objective of the case report is to bring awareness to clinicians about the variations in the origin and course of the right renal and ovarian vessels. This report may also be useful to clinicians performing invasive techniques and vascular surgeries.

\section{Case Report:}

During the gross anatomy dissection of the abdomen of an approximately 63 year old female cadaver, we observed variations in the origin and course of the renal artery (Fig 1). The right renal artery took its origin from the aorta as its ventral branch. Then it descended downwards and to the right, in front of the inferior vena cava and then entered the hilum of the right kidney. As the right renal artery passed in front of the inferior vena cava, it gave rise to the right ovarian artery. On its further course, the right renal artery was sandwiched between the inferior vena cava and the right ovarian vein (Fig 1). The right ovarian vein was enlarged and it received two considerably large tributaries from the pararenal pad of fat near the inferior pole of the right kidney. It opened into the inferior vena cava from anterior aspect of the vena cava. The right renal vein ascended upwards obliquely before ending in the inferior vena cava. 
Figure 1: Dissection showing the major vessels of the abdomen.

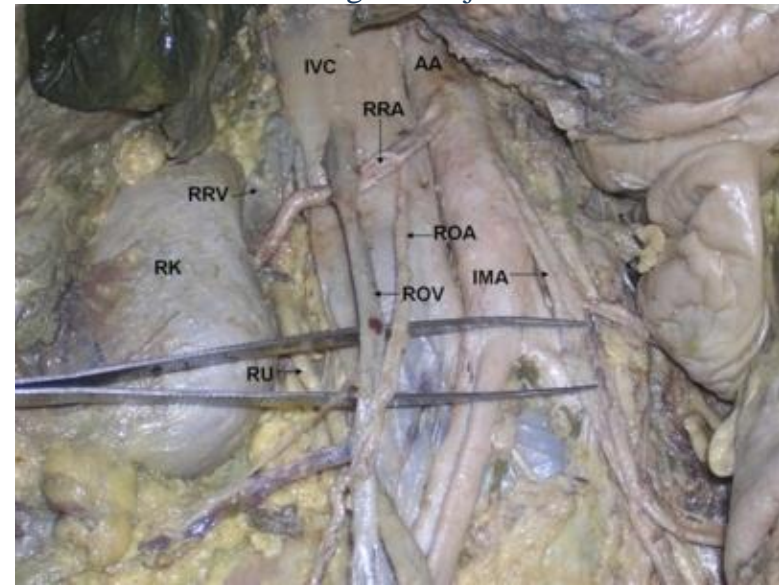

IVC - inferior vena cava, AA - abdominal aorta, RRV - right renal vein, RRA - right renal artery RK - right kidney, ROA - right ovarian artery, ROV - right ovarian vein, IMA - inferior mesenteric artery, RU - right ureter

\section{Discussion:}

The renal arteries are a pair of lateral branches of abdominal aorta. They arise from aorta just below the level of origin of the superior mesenteric artery. The accessory renal arteries are also seen frequently $\left({ }_{1,2,3}\right)$. Such arteries enter the kidney either above or below the hilum. Bayramoglu et al. (4) have reported bilateral additional renal arteries originating from the abdominal aorta. These additional renal arteries were associated with non-rotated kidneys with extra renal calices and pelvises. Most of the abnormalities in the renal arteries are due to the various developmental positions of the kidneys. (5). The supernumerary arteries supplying the lower pole have been reported. These arteries might arise from abdominal aorta (6) or inferior mesenteric artery. (7, 8).Dhar and Lal (9), found accessory renal arteries in $20 \%$ of the specimens they dissected. The anomaly was unilateral in $15 \%$ cases and bilateral on $5 \%$ of cases. Gonadal artery variations are also well known. In a study conducted by Cicekcibasi et al., (10) gonadal arteries showed variations in $8.8 \%$ of cases. The frequency of variation was more in male and it was more common on right side. Ovarian arteries may originate from aorta above the level of renal artery or they may take their origin from the renal or accessory renal arteries.

They may also give branches to diaphragm and suprarenal glands (11).Ovarian veins also show variation in the pattern of their termination. Right ovarian vein may open into the right renal vein instead of opening into inferior vena cava $\left({ }_{12}\right)$. The variations observed by us may be functionally, clinically, surgically and radiologically important. The origin of right renal artery from anterior aspect of aorta is unique and has not been reported yet. This type of origin may result in kinking of the aorta due to the weight of the kidney. Since the artery is sandwiched between the right ovarian vein and the gonadal vein, it might get compressed and lead to the malfunction of the kidney. If the renal artery compresses the terminal part of the ovarian vein, the ovarian vein in turn might get varicose. The knowledge of this type of variation of renal artery is of utmost importance to the surgeons doing kidney transplants and to the radiologists.

\section{References:}

[1]. Singh G, Ng YK, Bay BH. Bilateral accessory renal arteries associated with some anomalies of the ovarian arteries - a case study. Clin Anat. 1998;11(6):417-20

[2]. Satyapal KS, Haffejee AA, Singh B, Ramsaroop L. Robbs JV, Kalideen JM. Additional renal arteries: incidence and morphometry. SurgRadiol Anat. 2001; 23:33-8.

[3]. Bordei P, Sapte E, Iliescu D. Double renal arteries originating from the aorta. SurgRadiol Anat. 2004; 26:474-9.

[4]. Bayramoglu A, Demiryurek D, Erbil KM. Bilateral additional renal arteries and an additional right renal vein associated with unrotated kidneys. Saudi Med J. 2003; 24:535-7.

[5]. Moore KL and Persaud TVN. The Developing Human. Saunders, An Imprint of Elsevier. 7th Edition. pp. 293.

[6]. Shakeri AB, Shane Tubbs R, Shoja MM, Pezeshk P, Farahani RM, Khaki AA, Ezzati F, Seyednejad F. Bipolar supernumerary renal artery. SurgRadiol Anat. 2007;29:89-92.

[7]. Loukas M, Aparicio S, Beck A, Calderon R, Kennedy M. Rare case of right accessory renal artery originating as a common trunk with the inferior mesenteric artery: a case report. Clin Anat. 2005;18:530-5.

[8]. Gesase AP. Rare origin of supernumerary renal vessels supplying the lower pole of the left kidney. Ann Anat. 2007;189:53-8.

[9]. Dhar P, Lal K. Main and accessory renal arteries--a morphological study. Ital J AnatEmbryol. 2005;110:101-10.

[10]. Ciçekcibaşi AE, Salbacak A, Seker M, Ziylan T, Büyükmumcu M, Uysal II. The origin of gonadal arteries in human fetuses: anatomical variations. Ann Anat. 2002 May;184(3):275-9.

[11]. Rahman HA, Dong K, Yamadori T. Unique course of the ovarian artery associated with other variations. J Anat. 1993 Apr; 182 ( Pt 2):287-90.

[12]. Koc Z, Ulusan S, Oguzkurt L. Right ovarian vein drainage variant: is there a relationship with pelvic varices? Eur J Radiol. 2006 Sep;59(3):465-71. 